\title{
COVID-19 and domestic animals: Exploring the species barrier crossing, zoonotic and reverse zoonotic transmission of SARS-CoV-2
}

rajesh kumar ${ }^{1}$, seetha harilal ${ }^{1}$, Abdullah G. Al-Sehemi ${ }^{2}$, Mehboobali Paninipara ${ }^{2}$, tapan behl $^{3}$, Githa mathew ${ }^{4}$, and bijo mathew ${ }^{4}$

${ }^{1}$ Department of Pharmacy, Kerala University of Health Sciences, Thrissur, Kerala, India. ${ }^{2}$ 3Department of Chemistry, King Khalid University, Abha 61413, Saudi Arabia. ${ }^{3} 4$ Department of Pharmacology, Chitkara College of Pharmacy, Chitkara University, Punjab, India.

${ }^{4}$ Affiliation not available

July 1,2020

\begin{abstract}
To date, more than thirty animals were tested positive for SARS-CoV-2, all of them infected by humans with COVID-19. Some animal experiments suggested the possibility of an animal to animal transmission of SARS-CoV-2 and were seen in some cases of infected animals. Animal to human transmission was considered unlikely until investigations revealed the possibility of mink to human transmission of SARS-CoV-2 in the Netherlands. Studying the susceptibility of SARS-CoV-2 to domestic animals concluded that pigs, chicken, and ducks were not vulnerable to Covid-19; dogs showed less susceptibility to SARS-CoV-2 and cats as well as ferrets were seen susceptible to Covid-19. SARS-CoV-2 is seen crossing the species barrier, infecting humans from the wild with the source yet unclear, spreading from humans to humans quickly, humans to animals, animals to animals, and is likely to spread from animals to humans even though minimally. Animals appear somewhat resistant to SARS-CoV-2 transmission compared to humans who globally crossed eight million infection cases, and the infected animals mostly do not show many complications and recover quickly. Precautions are advised to prevent human to animal transmission of the virus, and in some areas, avoid animal to human spread of the virus. Further monitoring is required to assess the SARS-CoV-2 infection in animals as COVID-19 is a rapidly evolving condition worldwide.
\end{abstract}

\section{Introduction}

Covid-19, an epidemic started in Wuhan, was detected first in a 55-year-old in Hubei province with pneumonia of unknown etiology way back in November 2019 and has now developed as a pandemic causing chaos and threat to humankind worldwide by rapid infection and transmission of Severe Acute Respiratory Syndrome Coronavirus 2 (SARS-CoV-2). SARS-CoV-2 belongs to the beta coronavirus cluster and is thought to have originated from bats due to its similarity with Rhinolophus affinis bat (RaTGI3) genome (approximately 96\% similarity)(Wu and McGoogan, 2020; Zhou et al., 2020) followed by an intervention by possible intermediate hosts such as pangolin, snakes, or turtles.(Guo et al., 2020) The intermediate hosts are yet unknown, and further studies are required to elucidate the origin of transmission, which might aid in vaccine development and curbing the pandemic. However, a zoonotic transmission happened from the wild, and the virus might have been subjected to mutations via passing through intermediate hosts or after transmission to humans, before human-human transmission occurred as in Figure 1. The infectivity is based on ACE2 receptor susceptibility.(Andersen et al., 2020: 2) COVID-19 clinically manifests as asymptomatic as well as symptomatic forms, which can be mild or severe. As of June 16, 8,061,550 confirmed COVID-19 cases, and 440,290 death have been reported worldwide.("WHO Coronavirus Disease (COVID-19) Dashboard," 
n.d.) WHO and CDC advised social distancing in humans as well as pets, personal hygiene, respiratory hygiene, quarantine, or self- isolation on the detection of flu-like symptoms or if detected COVID-19 positive.("Advice for public," n.d.; CDC, 2020a) Covid-19 is carefully watched all over the world for potential zoonotic transmission. A few animals were tested SARS-CoV-2 positive worldwide when millions of people were tested SARS-CoV-2 positive across the globe, and pieces of evidence suggest that these animals contracted infection from close contact with SARS-CoV-2 positive people. Table 1 summarizes the list of domestic animals infected with SARS-CoV-2 reported in various countries, and the tests performed to confirm the infection. With the current evidence, animals seem difficult to get infected with SARS-CoV-2. The few infected animals were having a minor disease, mostly asymptomatic, with almost no immune response and quickly recovering. ("Confirmation of COVID-19 in Two Pet Cats in New York | CDC Online Newsroom | CDC," 2020; "SARS-CoV-2 in animals," n.d.)

\section{SARS-CoV-2 infection in domestic and other animal species}

\section{SARS-CoV-2 infection in dogs}

In the first case, in February, a Pomeranian dog was tested COVID-19 positive in Hong Kong.("Detection of low level of COVID-19 virus in pet dog," n.d.) The dog was having comorbidities and was subjected to serological as well as RT PCR tests. The PCR results were weakly positive for oral as well as nasal samples. The dog was living in quarantine, and there was no probability of transmission. The dog showed no marked clinical signs; no antibodies were detected, and there were no immune events; all of these proving the infection to be non-contagious.(Almendros, 2020) Another dog, a Covid-19 patient owned German shepherd, was found positive ("Pet dog tests positive for COVID-19 virus," n.d.) with viral genome resembling that isolated from the owner. There were no clinical symptoms, and the infection was non-contagious.("Promed Post - ProMED-mail," n.d.)

In North Carolina, USA, a pet dog, pug, was tested SARS-CoV-2 positive. It was showing mild symptoms and was living with a family were three members diagnosed with COVID-19. The oral swab showed positive results. There were another dog and a cat with the family and was tested negative. Later while doing confirmation tests, SARS-CoV-2 was unable to be isolated, nor immune response detected, which indicated the earlier weak positive result might be due to contamination from the SARS-CoV-2 positive household. The results suggest the importance of confirmation tests, including repeat sampling, RT-PCR, finding specific antibodies against the virus, and isolation of the virus. The conclusions regarding disease should be made after confirmation tests.("In-depth SARS-CoV-2 animal infection report," n.d.)

In the Netherlands, a pet American bulldog owned by a COVID-19 patient was tested SARS-CoV-2 positive. The dog showed severe breathing issues and was subjected to euthanasia. Antibodies against SARS-CoV-2 were seen in the serum. The breathing issues were not confirmed to be due to SARS-CoV-2.("In-depth SARS-CoV-2 animal infection report," n.d.)

In New York, USA, a German shepherd dog, one of the two living with their owners, a COVID-19 patient and another person with signs of COVID-19, was found positive and thought to have contracted the infection from its owners. The other dog showed SARS-CoV-2 specific antibodies but was asymptomatic. The dogs are expected to recover soon.("In-depth SARS-CoV-2 animal infection report," n.d.)

\section{SARS-CoV-2 infection in cats and feline species}

In Italy, a Covid-19 patient owned a pet cat that was found positive.("Coronavirus," 2020; "Promed Post ProMED-mail," n.d.) The cat was also asymptomatic, resembling the infected dogs. In Hong Kong, a Covid19 patient owned pet cat found positive and asymptomatic as well.("Promed Post - ProMED-mail," n.d.; "Pet cat tests positive for COVID-19," n.d.: 19) In Bronx zoo, New York City, a tiger with wheezing and dry cough was found positive. There was a zoo personnel diagnosed with COVID-19, and the animal is believed to have contracted the virus from human contact.("USDA APHIS | USDA Statement on the Confirmation of COVID-19 in a Tiger in New York," n.d.; James, 2020: 19) Three other lions and four tigers in the zoo, with appetite loss and cough, were also isolated. Later they were stable and were recovering.(Leroy et al., 2020) A 
lion was also tested SARS-CoV-2 positive. ("USDA APHIS | Confirmed cases of SARS-CoV-2 in Animals in the United States," n.d.) The tiger with confirmed SARS-CoV-2 was the only one tested because testing the large cats requires general anaesthesia. It is not feasible to anesthetize all those large cats. A fecal sample test was later designed, which can be utilized in large cats without general anaesthesia. The other seven animals enclosed in the zoo with the SARS-CoV-2 positive tiger, which showed mild respiratory symptoms, were tested using the fecal sample test. The seven animals showed SARS-CoV-2 positive results and were recovering.("SARS-CoV-2 in animals," n.d.) Two pet cats were tested SARS-CoV-2 positive in New York, USA, and they showed slight respiratory problems. The owner of one of the cats was a COVID-19 patient, and the other cat was living in a place having a large number of COVID-19 patients. The infection seen in the cats were not serious, and the cats seem to recover soon.("Confirmation of COVID-19 in Two Pet Cats in New York | CDC Online Newsroom | CDC," 2020; "SARS-CoV-2 in animals," n.d.)

A pet cat in Catalonia, Spain, owned by a COVID-19 patient, was tested SARS-CoV-2 positive. The gastrointestinal, as well as nasal samples, were weakly positive.("Detectan el primer positivo de un gato por coronavirus en España," 2020) Another cat, one among two cats owned by a COVID-19 patient, was tested SARS-CoV-2 positive. The oropharyngeal sample showed positive results. Follow up RT-PCR tests showed negative results. So, COVID-19 was unable to be confirmed through further tests.("https://www.oie.int/fileadmin/Home/eng/Our_scientific_expertise/docs/pdf/COV19/Nota_Gato\%20SARS-CoC-2_spain.pdf - Google Search," n.d.; "In-depth SARS-CoV-2 animal infection report," n.d.)

In France, a cat owned by a suspected COVID-19 patient was tested SARS-CoV-2 positive. It showed symptoms of respiratory as well as gastrointestinal illness. The rectal sample showed positive results. Another cat was also tested SARS-CoV-2 positive; the nasopharyngeal sample showed positive results. The cat was also living in an area with people suspected to have COVID-19 and showed cough as well as respiratory symptoms.("https://www.vet-alfort.fr/actualites-de-l-ecole/premier-chat-detecte-porteur-dusras-cov-2-en-france-par-l-umr-de-virologie - Google Search," n.d.; "COMMUNIQUÉ | www.envt.fr," n.d.; "In-depth SARS-CoV-2 animal infection report," n.d.)

In Germany, a COVID-19 patient owned pet cat was tested SARS-CoV-2 positive. The throat swab showed weakly positive results. Two other cats living in the same place were tested negative.("In-depth SARS-CoV-2 animal infection report," n.d.; "Questions and Answers on the COVID-19," n.d.)

In Wuhan, where SARS-CoV-2 infections started, serum samples from 102 cats were tested, in which 15 were found positive for the SARS-CoV-2 receptor-binding domain (RBD). Eleven of these cats showed antibodies against SARS-CoV-2. The study concludes that SARS-CoV-2 might have caused infection in the Wuhan cat population.(Zhang et al., 2020) In Russia, a cat was tested SARS-CoV-2 positive, where the nasal and throat samples showed positive results. The cat was quarantined and under observation.(Nikolay Vlasov, n.d.)

In a recent experiment to study the susceptibility of cats to SARS-CoV-2, three cats infected with the virus were kept in separate cages. Another cat was added to each of those cages and later it was found that SARS-CoV-2 was transmitted to the cage mate. The cats didn't show respiratory distress and were virus negative within a few days. But the study concluded that cats could transmit SARS-CoV-2 with prolonged contact.("COVID-19 and Animals | College of Veterinary Medicine," n.d.; Halfmann et al., 2020)

In Minnesota, USA, a cat was tested SARS-CoV-2 positive. The cat was owned by a COVID-19 patient and showed symptoms of respiratory disease. RT-PCR, as well as genome sequencing, showed positive results.("USDA APHIS | Confirmed cases of SARS-CoV-2 in Animals in the United States," n.d.; "Press Release," n.d.: 19)

In Illinois, USA, a cat that lived with COVID-19 positive people was tested SARS-CoV-2 positive, but further details were not available.("Public Health Officials Announce 1,156 New Confirmed Cases of Coronavirus Disease | IDPH," n.d.)

\section{SARS-CoV-2 infection 2 in minks}


In the Netherlands, the Minister of agriculture, food quality, and nature issued a letter and later updated the parliament regarding SARS-CoV-2 positive farmed minks.("COV-19/OIE SARS CoV\%202_infection_of_mink_in_the Netherlands - Google Search," n.d.) There were four infected mink farms. Health and safety precautions were implemented, and studies initiated. Several minks were tested positive, and there was an incidence of respiratory as well as gastrointestinal symptoms and mortality. SARS-CoV-2 RNA was seen in the lungs of 3 dead minks. SARS-CoV-2 RNA were also seen in all throat swabs and the majority of rectal swabs in another 18 dead minks. Viral loads were high in throat samples.("In-depth SARS-CoV-2 animal infection report," n.d.) Many caretakers in the farm were showing symptoms of COVID-19, and the animals were believed to be infected from those SARS-CoV-2 positive humans. The study's findings suggested SARSCoV-2 infection leading to pneumonia and death in minks even though there is a low infection and death rate in minks, and minks can also be asymptomatic. SARS-CoV-2 was found in dust samples inside the farm. Pregnant minks are vulnerable, and mink to mink transmission might have resulted in the viral spread inside the farms. Comparative analysis of sequences as well as phylogenetic mapping of the SARS-CoV-2 genome from the minks and the farm employees who were infected reveal the possibility of mink to human spread of the virus.(Zaken, 2020) The SARS-CoV-2 sequence isolated from the workers were not matching with the viral sequence from COVID-19 patients living in the adjacent areas and the sequence isolated from three of those workers were not matching with any of SARS-CoV-2 sequence isolated from COVID-19 patients in the Netherlands, all of these raising a question of mink to human spread of SARS-CoV-2.(Zaken, 2020) Workers were advised and started using personal protective equipment (PPE) while interacting with minks. ("SARS-CoV-2 in animals," n.d.; Oreshkova et al., 2020; "In-depth SARS-CoV-2 animal infection report," n.d.) Several cats near the mink farms were subjected to serological testing, and 7 of the 24 cats were tested SARS-CoV-2 positive with antibodies specific to the virus. SARS-CoV-2 RNA was found in one cat (Figure 2).("In-depth SARS-CoV-2 animal infection report," n.d.)

\section{Guidelines regarding SARS-CoV-2 infection in animals}

The US Department of Agriculture (USDA) defines animal SARS-CoV-2 infection as categories such as the suspect case, where the animal is having a high chance of SARS-CoV-2 exposure from humans and is showing clinical signs of the disease. The presumptive positive case includes RT-PCR positive animal. The confirmed positive includes SARS-CoV-2 sequence confirmation or antibodies specific to SARS-CoV-2, all tested at national veterinary services laboratories (NVSL).("In-depth SARS-CoV-2 animal infection report," n.d.) With the current knowledge of COVID-19, centers for disease control and prevention (CDC) suggest not to interact with pets if diagnosed with COVID-19 and not to allow pets interacting with other people or animals and to maintain 6 feet distance while in public areas. "Confirmation of COVID-19 in Two Pet Cats in New York | CDC Online Newsroom | CDC," 2020)

\section{Comparison of genome sequences and tissues in various species susceptible to SARS-CoV-2} infection

Viral infectivity depends on its affinity towards the host receptor and ACE2 has been identified as a suitable receptor for the binding and entry of SARS-CoV-2. In SARS-CoV-2, spike (S) protein is present, which consists of two subunits S1 and S2, among which S1 binds to the ACE-2 receptor, and S2 promotes viral fusion with the host cell membrane thereby creating a SARS-CoV-2- S-RBD complex.(Xia et al., 2020) But in animals, there seems to be a variation in susceptibility to infection, which can be due to amino acid variations in ACE2, seen among different species, which affects its binding to the SARS-CoV-2 S protein. The ACE2-S protein binding site of chimpanzees and macaque is similar to humans. While comparing human ACE2 to the ACE2 of other species, chickens show 11 differences, rodents show 10 differences, pigs show 6 differences, and cats show 3 differences.(J. Sun et al., 2020)

In humans, ACE2 expression can be observed in the heart, intestines, kidney, lungs, pancreas, and various other tissues exposed to air, including cornea.(K. Sun et al., 2020) Luan and his team, worked on analysing the key residues within the mammalian ACE2 responsible for recognition of spike protein. The key amino acids in S-protein responsible for its interaction with human ACE2 (hACE2) are L455, F486, Q493, S494, N501 and Y505, while K31, E35, D38, M82 and K353 are significant for ACE2-Receptor binding motif (RBM) 
among which the most important are K31 and K353.(Luan et al., 2020)

In rodents such as mice, the tissues, similar to humans excluding cornea and lungs, express murine ACE2 gene.(K. Sun et al., 2020) The weak susceptibility of murine ACE2 to SARS-CoV-2 in rodents such as mice and rats is due to the presence of three substitutions, D30N, Y83F, and K353H which render mice and rats ACE2 inactive. Unlike human ACE2, these substitutions do not cause direct contact to RBD.(Zhao et al., 2020) In rats, M82 and K353 amino acids observed in hACE2 is replaced by N82 and H353, whereas in mice, K31, M82 and K353 are replaced by N31, S82 and H 353. Murine species show 56\% similarity to hACE2. In Golden hamster, the amino acid M82 in hACE2 is replaced by N82.(Fam et al., 2020: 2; Luan et al., 2020)

In dogs, retina and skin express ACE2 gene.(K. Sun et al., 2020) Dog ACE2 consists of the substitutions, Q24L, D30E, D38E, M82T, and H34Y among which the presence of Q24L, M82T, and H34Y can cause disruption in ACE2- RBD interaction in contrast to D30E and D38E that are well tolerated.(Zhao et al., 2020) In dogs, the amino acids D38 and M82 in hACE2 are replaced by E38 and T82 showing $73 \%$ similarity to hACE2.(Fam et al., 2020: 2; Luan et al., 2020)

Cats have ACE2 gene expressed in regions of ear tips, lungs, retina, and skin.(K. Sun et al., 2020) Similar to dog ACE2, cats share four substitutions, Q24L, D30E, D38E, and M82T among which the initial and last changes can disrupt the ACE2-RBD interaction.(Zhao et al., 2020) In cats and ferrets, the amino acids D38 and M82 corresponding to hACE2 are replaced by E38 and T82 as in dogs and cat ACE2 orthologues is 77\% similar to hACE2.(Fam et al., 2020: 2; Luan et al., 2020) Taking into account, the livestock and pigs, ACE2 expression is observed in multiple tissues such as heart, liver, heart, and pig fat.(K. Sun et al., 2020)

\section{Proposing possible animal models against SARS-CoV-2}

Shi et al studied the probability of domestic animals to contract Covid-19. The study concluded that pigs, chicken, and ducks were not at all susceptible to Covid-19; dogs showed less susceptibility to SARS-CoV2 , and the viral replication was poor in all of these domestic animals. Cats, as well as ferrets, were seen susceptible to Covid-19.(Shi et al., 2020: 2) In ferrets, the type II pneumocytes seen in trachea bronchial airway submucosal glands as well as the epithelial serous cells show the presence of ACE2.(Van den Brand et al., 2008) When cats are compared to ferrets, the region of ACE2 that binds to the spike protein of SARS-CoV-2 exhibits two amino acid differences.(Van den Brand et al., 2008) Cats, as well as ferrets, have ACE2 which shows high homology to ACE2 of humans.(Shi et al., 2020: 2)

\section{Rodents as an animal model}

Among rodents, mice and rats are easy to handle and breed. But regarding SARS-CoV-2 infectivity they are not ideal be used as a model due to the substitution of certain residues in murine ACE2.(Cleary et al., 2020) Bao et al studied SARS-CoV-2 pathogenicity with human ACE2 carrying transgenic mice. The study confirmed the viral pathogenicity in hACE2 mouse which was not seen in SARS-CoV-2 infected wild mice and the animal model could be employed in developing therapy against SARS-CoV-2 or to understand further about COVID-19 pathogenesis.(Bao et al., 2020)

\section{Mesocricetus auratus (Syrian hamster) as an animal model}

Similar to other rodents, Golden hamster also has faster reproducibility. A simulation study by Chan et al showed that out of 29 amino acid residues present at the interface of ACE2 capable of interacting with SARS-CoV-2, 3-4 mutations were present at the interface attributing higher interacting interface between SARS-CoV-2- S protein and ACE2.(Chan et al., 2020) Sia and team investigated the pathogenesis and transmission of SARS-CoV-2 in Syrian hamster and concluded that they could be adopted as a model resembling mild cases of SARS-CoV-2 infection in humans.(Sia et al., 2020)

\section{Mustela putorius furo (ferrets) as an animal model}

Kim et al reported an animal model for studying SARS-CoV-2 infection. The infected ferrets showed signs of infection and were able to transmit the virus resulting in the presence of viral antigens and viral RNA in the transmitted ferrets. The study concluded ferrets as an infectious as well as transmission model of 
SARS-CoV-2 infection for further studies and development of therapy against SARS-CoV-2.(Kim et al., 2020) Blancho-Melo et al characterized SARS-CoV-2 infection in ferrets and postulated that the imbalance of host adaptive immune response and viral replication leads to the development of COVID-19.(Blanco-Melo et al., 2020: 19)

Felis catus (cat) as an animal model

Domestic cats are known to have close association with humans and can act as a potential carrier of SARS$\mathrm{CoV}-2$. Various studies and reports confirm that infected cats have viral shedding in feces and replication in the upper respiratory system and can transmit SARS-CoV-2 to non-infected cats via droplets. Hence cat as an animal model needs to be investigated further as these are easily available and closely associated with humans and might be useful as a model for vaccine and antiviral drug screening.(Mahdy, 2020)

Cynomolgus macaques as an animal model

Investigations on Cynomolgus macaques of both young and aged types demonstrated maximum damage on the respiratory tract, mainly pneumocytes type I and II. Replication in the lower and upper respiratory tracts revealed lung disease development and efficient transmission among the host. Alveolar lumina filled with edema fluid, lung consolidation, and pneumonia are observed post SARS-CoV-2 infection. They could be adopted as an asymptomatic model for SARS-CoV-2 as observed in COVID-19 patients.(Cleary et al., 2020; Rockx et al., 2020)

\section{Rhesus macaques as an animal model}

A study conducted by Munster and his team on adult Rhesus macaques showed recapitulation of COVID-19 moderate form as observed in humans. This model could demonstrate significant aberration in hematological parameters, chemokine and cytokine levels, nasal viral shedding, and interstitial pneumonia on $1^{\text {st }}$ or $3^{\text {rd }}$ day post inoculation with SARS-CoV-2, while IgG development could be detected in the $10^{\text {th }}$ day post inoculation. Even though the duration of the disease varies with that of humans, this model could indeed give an insight into the pathogenesis of the disease and aid in drug development.(Munster et al., 2020: 2) Another study by Shan et al confirmed the occurrence of pneumonia in SARS-CoV-2 infected Rhesus macaques .(Shan et al., 2020) The severity of pneumonia and aberration in various parameters such as hematological, inflammatory mediators, nasal and anal viral shedding are increased in aged groups compared with the young giving a possibility of exploring age-related phenomena in SARS-CoV-2 infection.(Yu et al., 2020: 19) Few other studies evaluating the DNA vaccines targeting S protein and the effectiveness of remdesivir and adenovirus-vectored vaccine were performed on Rhesus macaques ${ }^{4.9}$

\section{African green monkey as an animal model}

Due to the utility of African green monkeys (AGMs) in pathogenic respiratory diseases caused by viruses such as Nipah virus, Woolsey and team investigated this model's suitability against SARS-CoV-2. Even though current model lacked any infirm and apparent clinical illness, the aberration in hematological parameters, elevated inflammatory chemokines and cytokines were observed along with noticeable viral pneumonia, gastrointestinal (GI) abnormalities such as GI distress, thrombosis, as in humans, suggesting AGMs be a better model for investigating SARS-CoV-2 infection when compared to Cynomolgus macaques and Rhesus macaques .(Woolsey et al., 2020: 19)

\section{Conclusion}

SARS-CoV-2 is widely believed to be originated from animals of the wild, infected humans and formed a pandemic threatening mankind, putting a large population of the world under restrictions of several kinds. Various reports hint SARS-CoV-2 transmission from humans to animals, and many are cats. Studies suggest that cat to cat transmission of virus is possible via air in a limited manner. It escalates a concern of humancat-human virus spread, even though there is no evidence yet about a cat to human transmission. The tissues in exterior part of the body such as ear tips, retina, and skin of the dogs and cats, which are known to express ACE2, increases the risk of viral transmission. Current knowledge and evidence suggest that SARS-CoV-2 
can be transmitted from humans to some animals in certain situations. SARS-CoV-2 infected cases of cats, dogs, minks, tigers, and lions are various examples. But there is limited evidence of animals spreading the disease infecting humans. Animal to animal transmission of COVID-19 is mainly observed in feline species. Cats and ferrets were able to transmit the virus in various experiments. The first case of animal to human transmission was seen in the Netherlands' mink farms where workers were believed to be infected from the SARS-CoV-2 positive minks. The minks were believed to have contracted the infection from COVID-19 positive farm workers, then spreading the disease among themselves later infecting humans which led to workers using precautionary and protective measures while interacting with minks. The potential of SARS$\mathrm{CoV}-2$, crossing the species barrier should be investigated in a detailed manner because in many animals the infection is asymptomatic, difficult to detect, and the animals recover easily. In Wuhan, a study found about $15 \%$ of the cats sampled, to be showing evidence of infection either present or to have cured itself, which raises a question of undetected infection in the animal population. Such undetected infections in animals can lead to a transmission chain, spreading fast, and can even reach the wildlife, with chances of establishing a non-human viral reservoir in the wildlife, raising chances of further evolution of the virus forming a novel viral reservoir in animals which can spread among themselves or come back infecting humans. Therefore, testing needs to be done to ascertain the extent of SARS-CoV-2 spread among animals. For the progress in drug and vaccine development to curb this pandemic, suitable animal models that mimic human physiology is the need of the hour. Smaller animal models are less expensive and easy to study; however, the genomic sequence studies in mice and rats indicate the absence of ACE2-RBD interaction, making it unfit as a model for investigations related to SARS-CoV-2 infection. Alternative rodent models can be adopted as the usage of transgenic mice or Syrian hamster. Usage of higher animals such as Cynomolgus macaques, Rhesus macaques , and AGM models have an increased chance of reproducibility but are expensive and limited usage of animals in a group can be misleading statistically so result interpretation should be careful. However, there is some contradiction that needs to be addressed as studies on non-human primates such as Cynomolgus macaques andRhesus macaques have demonstrated limitations of reproducibility. Unlike rodents, ferrets develop cough reflex and are useful in virology and pharmacological studies. Cats are closely associated with humans and studies reveal cats can contribute to SARS-CoV-2 infection as well as transmission. Symptoms such as the development of pulmonary edema indicate further monitoring of cats for reproducibility of the severity of SARS-CoV-2 infection and its resemblance to human physiology. Genome sequencing studies propose that cats and ferrets can be used as probable animal models for investigating the SARS-CoV-2 infection and might aid in the development of vaccine and drug development to curb this pandemic (Figure 1).

\section{Declaration of Competing Interest}

The authors declare that they have no competing financial interests.

\section{Data availability statement}

All the data related with the work is available in the manuscript.

\section{Contributors}

R. K led the writing of the manuscript and developed the concept. S. Harilal, AGA, MP , TB and GEM developed the mechanistic approach, diagram. B.M developed the framework for the manuscript, edited and oversaw the drafting of the manuscript. All authors contributed to the content, drafting, and critical review of the manuscript.

\section{Funding}

The authors are thankful to institute of research and consulting studies at King Khalid University for funding this research through grant no $3-\mathrm{N}-20 / 21$ and the support of research centre for advanced material science is highly acknowledged.

\section{References}

Almendros, A., 2020: Can companion animals become infected with Covid-19? Vet. Rec. 186 , 388-389. 
American Veterinary Medical Association, n.d.: SARS-CoV-2 in animals [Online] Available at https://www.avma.org/resources-tools/animal-health-and-welfare/covid-19/sars-cov-2-animals-includingpets (accessed June 7, 2020).

American Veterinary Medical Association, n.d.: In-depth SARS-CoV-2 animal infection report [Online] Available at https://www.avma.org/resources-tools/animal-health-and-welfare/covid-19/depth-summaryreports-naturally-acquired-sars-cov-2-infections-domestic-animals-and-farmed-or (accessed June 8, 2020).

Andersen, K.G., A. Rambaut, W.I. Lipkin, E.C. Holmes, and R.F. Garry, 2020: The proximal origin of SARS-CoV-2. Nat. Med. 26 , 450-452.

Bao, L., W. Deng, B. Huang, H. Gao, J. Liu, L. Ren, Q. Wei, P. Yu, Y. Xu, F. Qi, Y. Qu, F. Li, Q. Lv, W. Wang, J. Xue, S. Gong, M. Liu, G. Wang, S. Wang, Z. Song, L. Zhao, P. Liu, L. Zhao, F. Ye, H. Wang, W. Zhou, N. Zhu, W. Zhen, H. Yu, X. Zhang, L. Guo, L. Chen, C. Wang, Y. Wang, X. Wang, Y. Xiao, Q. Sun, H. Liu, F. Zhu, C. Ma, L. Yan, M. Yang, J. Han, W. Xu, W. Tan, X. Peng, Q. Jin, G. Wu, and C. Qin, 2020: The pathogenicity of SARS-CoV-2 in hACE2 transgenic mice. Nature 1-6, DOI: 10.1038/s41586-020-2312-y.

Blanco-Melo, D., B.E. Nilsson-Payant, W.-C. Liu, S. Uhl, D. Hoagland, R. Møller, T.X. Jordan, K. Oishi, M. Panis, and D. Sachs, 2020: Imbalanced host response to SARS-CoV-2 drives development of COVID-19. Cell .

CDC, 2020a (11. February): Centers for Disease Control and Prevention, Coronavirus Disease 2019 (COVID19) [Online] Available at https://www.cdc.gov/coronavirus/2019-ncov/daily-life-coping/animals.html (accessed June 9, 2020).

CDC, 2020b (29. March): Centers for Disease Control and Prevention, Coronavirus Disease 2019 (COVID-19) - Symptoms [Online] Available at https://www.cdc.gov/coronavirus/2019-ncov/symptomstesting/symptoms.html (accessed April 2, 2020).

Chan, J.F.-W., A.J. Zhang, S. Yuan, V.K.-M. Poon, C.C.-S. Chan, A.C.-Y. Lee, W.-M. Chan, Z. Fan, H.-W. Tsoi, and L. Wen, 2020: Simulation of the clinical and pathological manifestations of Coronavirus Disease 2019 (COVID-19) in golden Syrian hamster model: implications for disease pathogenesis and transmissibility. Clin. Infect. Dis.

Cleary, S.J., S.C. Pitchford, R.T. Amison, R. Carrington, C.L. Robaina Cabrera, M. Magnen, M.R. Looney, E. Gray, and C.P. Page, 2020: Animal models of mechanisms of SARS-CoV-2 infection and COVID-19 pathology.

Br. J. Pharmacol.

Fam, B.S., P. Vargas-Pinilla, C.E.G. Amorim, V.A. Sortica, and M.C. Bortolini, 2020: ACE2 diversity in placental mammals reveals the evolutionary strategy of SARS-CoV-2. Genet. Mol. Biol.43 .

Guo, Y.-R., Q.-D. Cao, Z.-S. Hong, Y.-Y. Tan, S.-D. Chen, H.-J. Jin, K.-S. Tan, D.-Y. Wang, and Y. Yan, 2020: The origin, transmission and clinical therapies on coronavirus disease 2019 (COVID-19) outbreak - an update on the status. Mil. Med. Res. 7 , 11, DOI: 10.1186/s40779-020-00240-0.

Halfmann, P.J., M. Hatta, S. Chiba, T. Maemura, S. Fan, M. Takeda, N. Kinoshita, S. Hattori, Y. SakaiTagawa, K. Iwatsuki-Horimoto, M. Imai, and Y. Kawaoka, 2020: Transmission of SARS-CoV-2 in Domestic Cats.N. Engl. J. Med. 0 , null, DOI: 10.1056/NEJMc2013400.

Hong Kong's Information Services Department, n.d.: Pet cat tests positive for COVID-19 [Online] Available at http://www.news.gov.hk/eng/2020/03/20200331/20200331_220128_110.html (accessed May 18, 2020).

James, A., 2020 (5. April): WPDE, A Tiger at Bronx Zoo Tests Positive for COVID-19 [Online] Available at https://wpde.com/news/coronavirus/a-tiger-at-bronx-zoo-tests-positive-for-covid-19 (accessed May 18, 2020). 
Kim, Y.-I., S.-G. Kim, S.-M. Kim, E.-H. Kim, S.-J. Park, K.-M. Yu, J.-H. Chang, E.J. Kim, S. Lee, and M.A.B. Casel, 2020: Infection and rapid transmission of SARS-CoV-2 in ferrets. Cell Host Microbe .

La Vanguardia, , 2020 (8. May): Detectan el primer positivo de un gato por coronavirus en España [Online] Available at https://www.lavanguardia.com/ciencia/20200508/481017525884/primer-gato-sars-cov-2-covidinfectado-espana.html (accessed June 8, 2020).

Leroy, E.M., M.A. Gouilh, and J. Brugère-Picoux, 2020: The risk of SARS-CoV-2 transmission to pets and other wild and domestic animals strongly mandates a one-health strategy to control the COVID-19 pandemic. One Health .

Luan, J., Y. Lu, X. Jin, and L. Zhang, 2020: Spike protein recognition of mammalian ACE2 predicts the host range and an optimized ACE2 for SARS-CoV-2 infection. Biochem. Biophys. Res. Commun.

Mahdy, M., 2020: An overview of SARS-CoV-2 and animal infection.Preprints .

Minnesota Board of Animal Health, n.d.: Press Release: Household cat confirmed with virus that causes COVID-19 [Online] Available at https://content.govdelivery.com/accounts/MNBAH/bulletins/28eac81 (accessed June 14, 2020).

Munster, V.J., F. Feldmann, B.N. Williamson, N. van Doremalen, L. Pérez-Pérez, J. Schulz, K. Meade-White, A. Okumura, J. Callison, and B. Brumbaugh, 2020: Respiratory disease in rhesus macaques inoculated with SARS-CoV-2. Nature 1-7.

Nikolay Vlasov n.d.: Oie SARS-CoV-2, Russia [Online] Available at https://www.oie.int/wahis_2/public/wahid.php/Reviewreport/Review?page_refer $=$ MapFullEventReport\&reportid $=34443 \&$ newlang $=$ en (accessed June 9, 2020).

Oreshkova, N., R.-J. Molenaar, S. Vreman, F. Harders, B.B.O. Munnink, R.W.H. Honing, N. Gerhards, P. Tolsma, R. Bouwstra, and R. Sikkema, 2020: SARS-CoV2 infection in farmed mink, Netherlands, April 2020.bioRxiv .

Rockx, B., T. Kuiken, S. Herfst, T. Bestebroer, M.M. Lamers, B.B.O. Munnink, D. de Meulder, G. van Amerongen, J. van den Brand, and N.M. Okba, 2020: Comparative pathogenesis of COVID-19, MERS, and SARS in a nonhuman primate model. Science $368,1012-1015$.

Shan, C., Y.-F. Yao, X.-L. Yang, Y.-W. Zhou, J. Wu, G. Gao, Y. Peng, L. Yang, X. Hu, and J. Xiong, 2020: Infection with novel coronavirus (SARS-CoV-2) causes pneumonia in the rhesus macaques. Nature .

Shi, J., Z. Wen, G. Zhong, H. Yang, C. Wang, B. Huang, R. Liu, X. He, L. Shuai, and Z. Sun, 2020: Susceptibility of ferrets, cats, dogs, and other domesticated animals to SARS-coronavirus 2. Science .

Sia, S.F., L.-M. Yan, A.W. Chin, K. Fung, K.-T. Choy, A.Y. Wong, P. Kaewpreedee, R.A. Perera, L.L. Poon, and J.M. Nicholls, 2020: Pathogenesis and transmission of SARS-CoV-2 in golden hamsters.Nature 1-7.

Sun, J., W.-T. He, L. Wang, A. Lai, X. Ji, X. Zhai, G. Li, M.A. Suchard, J. Tian, and J. Zhou, 2020: COVID-19: epidemiology, evolution, and cross-disciplinary perspectives. Trends Mol. Med.

Sun, K., L. Gu, L. Ma, and Y. Duan, 2020: Atlas of ACE2 gene expression in mammals reveals novel insights in transmission of SARS-Cov-2.BioRxiv .

Takayama, K., 2020: In vitro and Animal Models for SARS-CoV-2 research.

Trends Pharmacol. Sci.

The Brussels Times, , 2020 (27. March): Coronavirus: Belgium reaches 7,284 confirmed cases [Online] Available at https://www.brusselstimes.com/all-news/belgium-all-news/102984/coronavirus-belgiumreaches-7284-confirmed-cases/ (accessed May 18, 2020). 
Van den Brand, J.M.A., B.L. Haagmans, L. Leijten, D. van Riel, B.E. Martina, A. Osterhaus, and T. Kuiken, 2008: Pathology of experimental SARS coronavirus infection in cats and ferrets. Vet. Pathol.45 , 551-562.

Wang, H., F. Wang, H. Wang, and Q. Zhao, 2020: Potential infectious risk from the pets carrying SARSCoV-2. Travel Med. Infect. Dis.

Woolsey, C., V. Borisevich, A.N. Prasad, K.N. Agans, D.J. Deer, N.S. Dobias, J.C. Heymann, S.L. Foster, C.B. Levine, and L. Medina, 2020: Establishment of an African green monkey model for COVID-19.bioRxiv

Wu, Z., and J.M. McGoogan, 2020: Characteristics of and important lessons from the coronavirus disease 2019 (COVID-19) outbreak in China: summary of a report of 72314 cases from the Chinese Center for Disease Control and Prevention. Jama 323 , 1239-1242.

Xia, S., M. Liu, C. Wang, W. Xu, Q. Lan, S. Feng, F. Qi, L. Bao, L. Du, and S. Liu, 2020: Inhibition of SARS-CoV-2 (previously 2019-nCoV) infection by a highly potent pan-coronavirus fusion inhibitor targeting its spike protein that harbors a high capacity to mediate membrane fusion. Cell Res. 30 , 343-355.

Yu, P., F. Qi, Y. Xu, F. Li, P. Liu, J. Liu, L. Bao, W. Deng, H. Gao, and Z. Xiang, 2020: Age-related rhesus macaque models of COVID-19.Anim. Models Exp. Med. 3 , 93-97.

Zaken, M. van A., 2020 (19. May): New results from research into COVID-19 on mink farms - News item - Government.nl [Online] Available at https://www.government.nl/latest/news/2020/05/19/new-results-fromresearch-into-covid-19-on-mink-farms (accessed June 8, 2020). nieuwsbericht.

Zhang, Q., H. Zhang, K. Huang, Y. Yang, X. Hui, J. Gao, X. He, C. Li, W. Gong, Y. Zhang, C. Peng, X. Gao, H. Chen, Z. Zou, Z. Shi, and M. Jin, 2020: SARS-CoV-2 neutralizing serum antibodies in cats: a serological investigation. bioRxiv 2020.04.01.021196, DOI: 10.1101/2020.04.01.021196.

Zhao, X., D. Chen, R. Szabla, M. Zheng, G. Li, P. Du, S. Zheng, X. Li, C. Song, and R. Li, 2020: Broad and differential animal ACE2 receptor usage by SARS-CoV-2. bioRxiv .

Zhou, P., X.-L. Yang, X.-G. Wang, B. Hu, L. Zhang, W. Zhang, H.-R. Si, Y. Zhu, B. Li, and C.-L. Huang, 2020: A pneumonia outbreak associated with a new coronavirus of probable bat origin. nature579 , 270-273.

, 2020 (22. April): Confirmation of COVID-19 in Two Pet Cats in New York | CDC Online Newsroom | CDC [Online] Available at https://www.cdc.gov/media/releases/2020/s0422-covid-19-cats-NYC.html (accessed June 7, 2020).

N.d.: WHO Coronavirus Disease (COVID-19) Dashboard [Online] Available at https://covid19. who.int/?gclid=CjwKCAjw_qb3BRAVEiwAvwq6VnslTnA8mMyCe5vAYhR2Dhb7kN7YLv8pkUHz7Q8qCHW_9OZ3CMN9RoCK7EQAvD_BwE (accessed June 18, 2020).

N.d.: Advice for public [Online] Available at https://www.who.int/emergencies/diseases/novel-coronavirus2019/advice-for-public (accessed June 16, 2020).

N.d.: Detection of low level of COVID-19 virus in pet $\operatorname{dog}$ [Online] Available at https://www.info.gov.hk/gia/general/202002/28/P2020022800013.htm (accessed May 18, 2020).

N.d.: Pet $\operatorname{dog}$ tests positive for COVID-19 virus [Online] Available at https://www.info.gov.hk/gia/general/202003/19/P2020031900606.htm (accessed May 18, 2020).

N.d.: Promed Post - ProMED-mail [Online] Available at https://promedmail.org/promed-post/ (accessed May 18, 2020).

N.d.: USDA APHIS | USDA Statement on the Confirmation of COVID-19 in a Tiger in New York [Online] Available at https://www.aphis.usda.gov/aphis/newsroom/news/sa_by_date/sa-2020/ny-zoo-covid-19 (accessed June 8, 2020). 
N.d.: USDA APHIS | Confirmed cases of SARS-CoV-2 in Animals in the United States [Online] Available at https://www.aphis.usda.gov/aphis/ourfocus/animalhealth/SA_One_Health/sars-cov-2-animals-us (accessed June 8, 2020).

N.d.: $\quad$ https://www.oie.int/fileadmin/Home/eng/Our_scientific_expertise/docs/pdf/COV19/Nota_Gato\%20SARS-CoC-2_spain.pdf - Google Search [Online] Available at https://www.google.com/search?rlz=1C1CHZL_enIN721IN721\&sxsrf=ALeKk00wzWwyGWP1yJEgvLcP4u2TMsopKQ\%3A15 EPx5SD-Ao\&q=https\%3A\%2F\%2Fwww.oie.int\%2Ffileadmin\%2FHome\%2Feng\%2FOur_scientific_expertise\%2Fdocs\%2Fpdf\%2FCOV-19\%2FNota_Gato\%2520SARS-CoC-2_spain.pdf\&oq=https\%3A\%2F\%2Fwww.oie.int\%2Ffileadmin $\% 2 F H o m e \% 2 F e n g \% 2 F O u r \_s c i e n-$ tific_expertise\%2Fdocs\%2Fpdf\%2FCOV-19\%2FNota_Gato\%2520SARS-CoC-2_spain.pdf\&gs_lcp=CgZwc3ktYWIQA1C5EVi5EWD4FGgAcAB4AIABAIgBAJIBAJgBBqABAqABAaoBB2d3cy13aXo\&sclient=psyab\&ved=0ahUKEwjrgePx9fDpAhWbzDgGHUfKAK8Q4dUDCAw\&uact=5 (accessed June 8, 2020).

N.d.: $\quad$ https://www.vet-alfort.fr/actualites-de-l-ecole/premier-chat-detecte-porteur-dusras-cov-2-en-france-par-l-umr-de-virologie - Google Search [Online] Available at https://www.google.co.in/search?sxsrf=ALeKk01xWhdA0vYzhSDOV6ZoFQwqrfhQSg\%3A1591662235156\&source=hp\&ei= EPoa-1uAo\&q=https\%3A\%2F\%2Fwww.vet-alfort.fr\%2Factualites-de-l-ecole\%2Fpremier-chatdetecte-porteur-du-sras-cov-2-en-france-par-l-umr-de-virologie\&oq=https $\% 3 \mathrm{~A} \% 2 \mathrm{~F} \% 2 \mathrm{~F} w w w . v e t-$ alfort.fr\%2Factualites-de-l-ecole\%2Fpremier-chat-detecte-porteur-du-sras-cov-2-en-france-par-l-umr-devirologie\&gs_lcp=CgZwc3ktYWIQAzIHCCMQ6gIQJzIHCCMQ6gIQJzIHCCMQ6gIQJzIHCCMQ6gIQJzIHCCMQ6gIQJzIH ab\&ved=0ahUKEwiOiILxu_PpAhUKwjgGHaFXDacQ4dUDCAc\&uact=5 (accessed June 9, 2020).

N.d.: COMMUNIQUÉ | www.envt.fr [Online] Available at http://www.envt.fr/content/communiqu\%C3\%A9 (accessed June 9, 2020).

N.d.: Questions and Answers on the COVID-19: OIE - World Organisation for Animal Health [Online] Available at https://www.oie.int/en/scientific-expertise/specific-information-and-recommendations/questionsand-answers-on-2019novel-coronavirus (accessed June 9, 2020).

N.d.: COVID-19 and Animals | College of Veterinary Medicine [Online] Available at https://vet.osu.edu/about-us/news/covid-19-and-animals (accessed June 9, 2020).

N.d.: Public Health Officials Announce 1,156 New Confirmed Cases of Coronavirus Disease | IDPH [Online] Available at https://www.dph.illinois.gov/news/public-health-officials-announce-1156-new-confirmed-casescoronavirus-disease (accessed June 14, 2020).

N.d.: COV-19/OIE SARS CoV\%202_infection_of_mink_in_the Netherlands - Google Search [Online] Available at https://www.google.co.in/search?hl=en\&q=COV-19/OIE+SARS+CoV\%25202_infection_of_mink_in_the+Netherlands (accessed June 8, 2020). 


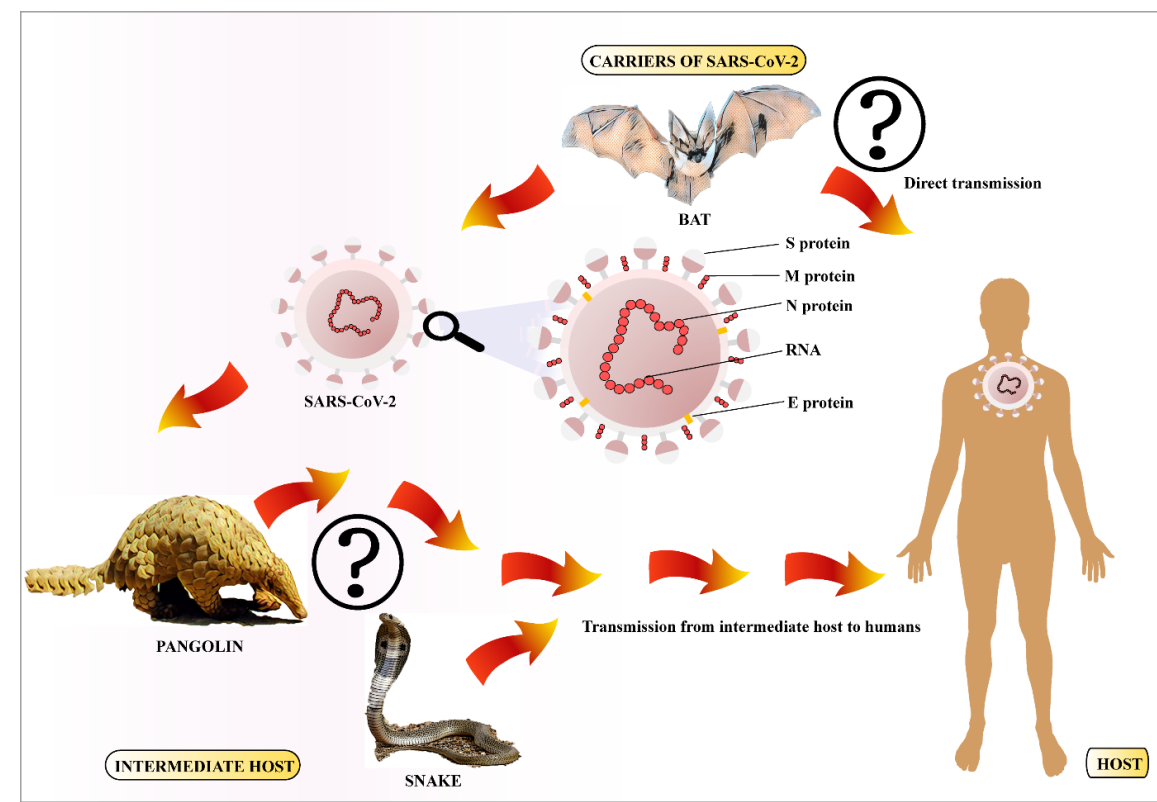

Figure 1. Zoonotic transmission of SARS-CoV-2.

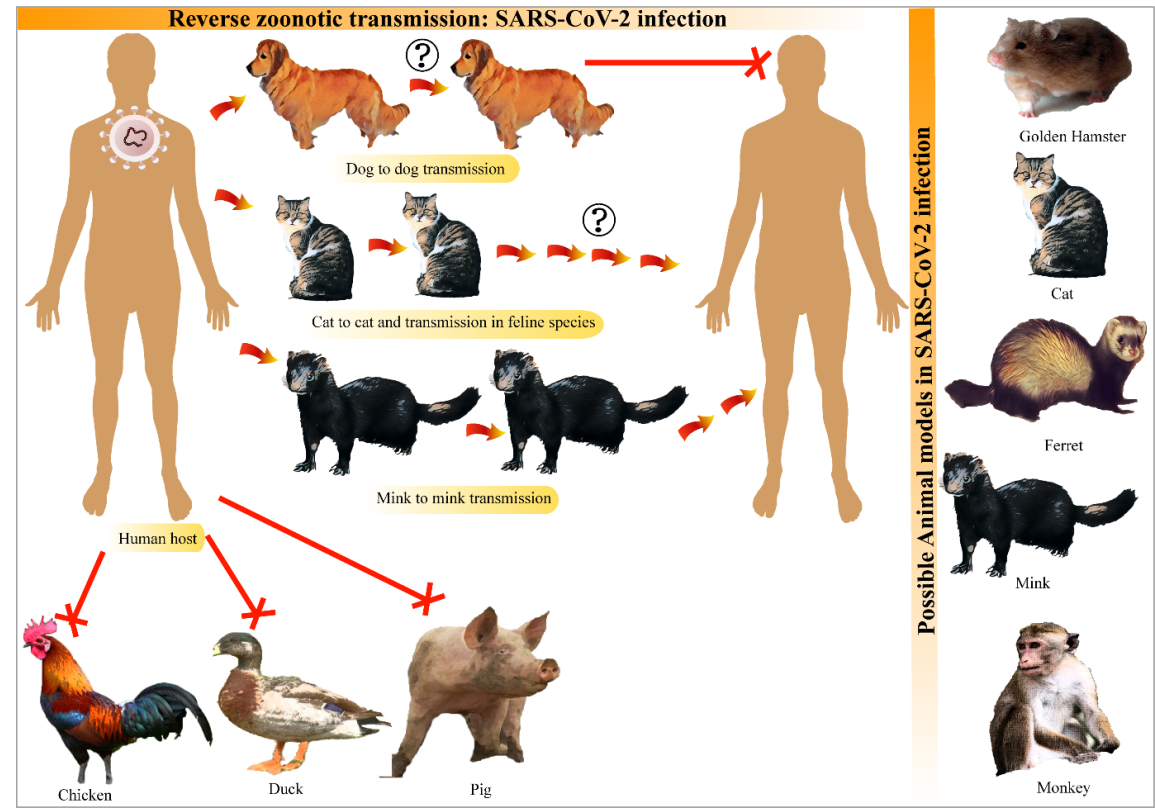

Figure 2. Reverse zoonotic transmission of SARS-CoV-2 and possible animal models in SARSCoV-2 infection.

Table 1. Summary of domestic animals infected with SARS-CoV-2 in various countries with tests performed to confirm the infection. ("In-depth SARS-CoV-2 animal infection report," n.d.)

\begin{tabular}{lll}
\hline Date of events/reports & Animals & Countr \\
\hline SARS-CoV-2 infection in dogs & SARS-CoV-2 infection in dogs & SARS-
\end{tabular}




\begin{tabular}{lll}
\hline Date of events/reports & Animals & Countr \\
\hline $27^{\text {th }}$ February 2020 & One dog & Hong K \\
$18^{\text {th }}$ March 2020 & One dog & Hong K \\
$28^{\text {th }}$ April 2020 & One dog & North \\
$15^{\text {th }}$ May 2020 & One dog & Netherl \\
$2^{\text {nd }}$ June 2020 & One dog & USA \\
SARS-CoV-2 infection in cats and feline species & SARS-CoV-2 infection in cats and feline species & SARS- \\
$18^{\text {th }}$ March 2020 & One cat & Belgium \\
$27^{\text {th }}$ March 2020 & One tiger & New Yo \\
$27^{\text {th }}$ March 2020 & One lion & New Yo \\
$27^{\text {th }}$ March 2020 & Three lions and four tigers \\
$30^{\text {th }}$ March 2020 & One cat & New Yo \\
$1^{\text {st }}$ and $6^{\text {th }}$ April 2020 & Two cats & Hong K \\
$1^{\text {st }}$ May 2020 & One cat & New Yo \\
$8^{\text {th }}$ May 2020 & One cat & France \\
$12^{\text {th }}$ May 2020 & One cat & Spain \\
$13^{\text {th }}$ May 2020 & One cat & France \\
$15^{\text {th }}$ May 2020 & Three cats & German \\
$18^{\text {th }}$ May 2020 & One cat & Netherl \\
$21^{\text {st }}$ May 2020 & One cat & Russia \\
$25^{\text {th }}$ May 2020 & Four cats & Spain \\
3 rd June 2020 & One cat & Netherl \\
5 th June 2020 & One cat & Minnes \\
SARS-CoV-2 infection in minks & SARS-CoV-2 infection in minks & Illinois, \\
$26^{\text {th }}$ April and $8^{\text {th }}$ May 2020 & Many minks & SARS- \\
\hline
\end{tabular}

